\title{
Pierre Duhem's Good Sense as a guide to Theory Choice
}

\author{
Milena Ivanova \\ Department of Philosophy \\ University of Bristol \\ 9 Woodland Road \\ Bristol BS8 1TB \\ United Kingdom
}

\begin{abstract}
This paper examines Duhem's concept of good sense as an attempt to support a non rule-governed account of rationality in theory choice. Faced with the underdetermination of theory by evidence thesis and the continuity thesis, Duhem tried to account for the ability of scientists to choose theories that continuously grow to a natural classification. I will examine the concept of good sense and the problems that stem from it. I will also present a recent attempt by David Stump to link good sense to virtue epistemology. I will argue that even though this approach can be useful for the better comprehension of the concept of good sense, there are some substantial differences between virtue epistemologists and Duhem. In the light of this reconstruction of good sense, I will propose a possible way to interpret the concept of good sense, which overcomes the noted problems and fits better with Duhem's views on scientific method and motivation in developing the concept of good sense.
\end{abstract}


Keywords: good sense, natural classification, novel predictions, theoretical virtues, unification, virtue epistemology

\section{Introduction}

Having advanced the continuity thesis and the underdetermination of theory by evidence thesis, Pierre Duhem was faced with the problem of how scientists could choose between theories with equal empirical consequences. His solution was based on the concept of good sense by which he tried to advance a theory of rationality that combines both descriptive and normative elements. Being an important physicist, historian and philosopher of science, Duhem was well aware of the scientific practice and tried to describe it, but also tried to develop a normative account of rationality that should guide scientists when faced with the problem of theory choice.

In this paper I explain how Duhem's account of scientific method and his concept of good sense can contribute to the current debate on rationality in theory choice. In section 2 , I review how the problem of theory choice arises. Section 3 examines how the concept of good sense was developed to account for the problem of underdetermination, but also some difficulties that arise from it. Section 4 presents a recent attempt to link the concept of good sense to virtue epistemology, advanced by David Stump. Finally, in section 5, I develop an interpretation of the concept of good sense which I believe fits better with Duhem's view of scientific method. I propose that by viewing good sense as the properties of an ideal scientist, we can overcome some of the difficulties faced by Duhem's original development of the concept of good sense.

2. Natural classification, underdetermination and continuity

Taking theories to be abstract systems that summarize and classify in a logical manner a set of experimental laws, Duhem opposed any attempt to explain the phenomena by searching 
for a reality hidden under the veil of appearances. He initially adopted instrumentalism (Duhem, 1892), holding that theories should aim simply at saving the phenomena and not at revealing whether there is a distinct reality behind the phenomena we observe. His central idea was that science can be practiced in a satisfactory manner without scientists being concerned with whether there are unobservable entities causing the observable phenomena and whether they should aim to describe their nature. This fact renders physics autonomous of metaphysics.

According to Duhem, the history of science supports the view that theories are not proposed in order to explain reality by positing unobservable entities, but as representations of experimental laws. However, he also recognized that history teaches us that new theories usually build on old ones, evolve from old ones, become part of a unified system and manage to predict novel facts. These facts about science needed to be accounted for and Duhem tried to do so by developing the concept of natural classification, which aimed to draw a middle way between instrumentalism and scientific realism. Physical theory is not just a representation of the laws discovered by the experimentalist but also a classification of these laws. The fact that this classification manages to unify wide variety of phenomena shows us that it cannot simply be an artificial classification created by the physicist, but instead that it becomes more and more natural ${ }^{1}$. According to Duhem, even though physical theory cannot reveal the unobservable reality, it can still teach us something of the world, because "the more complete it becomes, the more we apprehend that the logical order in which theory orders experimental laws is the reflection of an ontological order, the more we suspect that the relations it establishes among the data of observation correspond to real relations among things" (Duhem, 1954, p. 26). Since physical theory is a representation and not an explanation, even at the 'ideal end of science' it will not reveal the real causes of the

\footnotetext{
${ }^{1}$ For a detailed discussion of Duhem's concept of natural classification and scientific realism, see Lugg, A. (1990), McMullin, E. (1990) and Psillos, S. (1999).
} 
phenomena. That is, because we are epistemically restricted, we can never "strip reality of the appearances covering it like a veil, in order to see the bare reality itself" (Ibid., p. 7 ). But the more successful in their predictions our theories are, the more they manage to uncover the relations that hold among these 'realities' or 'things'. Duhem's view is best understood as structural realism ${ }^{2}$, since a natural classification will provide the relations that hold among the unobservable entities, as Duhem noted "real relations among things", without revealing their properties. According to Duhem, "physical theory through its successive advances tends to arrange experimental laws in an order more and more analogous to the transcendent order according to which the realities are classified" (Ibid., p. 297).

The concept of natural classification was introduced to account for the novel predictive success and the unifying power of theories. But in the light of the underdetermination thesis, Duhem could not account for the continuity of science. Having studied in detail ancient and medieval science (Duhem, 1969), Duhem came to support the view that science does not proceed by scientific revolutions but is a continuous procedure. According to him, "In the course of this long and laborious birth, we can follow the slow and gradual transformation through which the theoretical system evolves; but at no time can we see a sudden and arbitrary creation of new hypotheses" (Ibid., p. 252). The concept of natural classification is important for understanding Duhem's view of the continuity in science since in the transition from old to new theories, what is preserved is the natural classification and not the metaphysical commitments of a theory. But how could theories proceed and become part of a unified natural classification if scientists were faced with empirically equivalent alternatives?

\footnotetext{
${ }^{2}$ John Worrall (1989) has argued that Duhem's view is best understood as Structural Realism. According to structural realists, even though theories cannot describe the nature of the unobservable reality, they can reveal its structure that is otherwise hidden under the veil of appearances.
} 
The problem of underdetermination for Duhem arises from the holistic character of confirmation $^{3}$. According to Duhem, when we test a theory, we never test it in isolation from auxiliary assumptions, and when the experiment does not give us the expected outcome, either the hypothesis we are testing or one (or more) of the auxiliary assumptions might be false. The experiment cannot tell us which might be false: "the only thing the experiment teaches us is that among the propositions used to predict the phenomena and to establish whether it would be produced, there is at least one error; but where this error lies is just what it does not tell us" (Duhem, 1954, p. 185). That means that neither logic nor particular experience can determine in which hypothesis the problem lies.

This holistic character of theory testing led Duhem to argue that we could always save a theory from refutation, that is, to make it fit the empirical evidence, by changing the auxiliary hypotheses (Ibid, p. 216). In this way we can produce different theories that will equally well fit the empirical data. This leads to the thesis of the underdetermination of the theory by evidence (UTE) because empirical evidence cannot help us when we have to decide between two empirically equivalent rival theories. UTE is especially important since we usually think of experiment as the empirical test we can perform in order to judge whether our theory is satisfactory when its consequences are compared with the evidence. If the experiment cannot guide us to decide between rival theories, we seem to lack an empirical source of decision. In the current debate, we can distinguish arguments of weak and strong underdetermination ${ }^{4}$. The former, which was developed by Duhem, allows for future empirical evidence to discern between two rival equivalent hypotheses. The latter holds that in principle we could never,

\footnotetext{
${ }^{3}$ It is important to stress that holism and underdetermination are two distinct theses, the former is concerned with confirmation and the latter with theory choice. This distinction is explained in Hoefer and Rosenberg (1994).

${ }^{4}$ The distinction between weak and strong underdetermination is discussed in Ladyman (2002). Hoefer and Rosenberg (1994) also distinguish between local and global underdetermination.
} 
based only on our experience, be able to choose one hypothesis over another because they will always be compatible with the same evidence.

One way to address the problem of underdetermination is simply to hold that no choice can be made in such cases. Another is to choose among the two theories with pragmatic criteria. Duhem recognized that UTE would not be problematic to those that accept conventionalism and support that one can adopt some theories to save some phenomena, other theories to save other phenomena. He stressed that "if we confine ourselves simply to logic, we cannot prevent a physicist from representing by several incompatible theories diverse groups of laws, or even a single group of laws; we cannot condemn incoherence in physical theory" (Duhem, 1954, p. 111). There is no logical contradiction in using different theories as instruments to save different sets of phenomena, given that we do not mix up these theories. Still, Duhem strongly believed that physical theory should be logically unified, even though neither logic nor experience lead to this conclusion. This is a strong "innate feeling of ours" (Ibid., p. 102), an aspiration towards unity in science, which cannot be justified but also cannot be stifled ${ }^{5}$. Duhem believed that theory cannot be just a convenient system; it is logically organized, unified and intended to lead towards natural classification. That is why he believed that rational choice in science is possible and tried to account for it by developing the concept of good sense.

\section{Good Sense and Rational Choice}

Duhem noticed that when experience is not enough for choosing among two alternative theories with the same empirical consequences, various criteria need to be taken into consideration. These include the scope of the theory, the number of hypotheses (Duhem, 1892, p. 22), novel predictions (Duhem, 1954, p. 28, p. 195), comparability with other theories (Ibid., p. 221, p. 255), simplicity, unification into a single system of hypotheses

\footnotetext{
${ }^{5}$ Duhem's thought here can be seen as similar to Kant's regulative principles of reason.
} 
(Ibid., p. 294), and elegance and convenience. Duhem recognized that the employment of such criteria is indispensable in theory choice; however, an algorithm that describes how these theoretical virtues should be used cannot be provided, because in order to employ them scientists need to make judgments and assessments that cannot be determined in a strict algorithmic way ${ }^{6}$. When faced with the problem of theory choice, one scientist may choose to favor a simple theory, while another may neglect simplicity and favor a theory with explanatory power. Apart from the fact that we cannot provide an algorithm as to which virtue should be employed and valued over the others, it is also difficult to define what each virtue is and how it is measured. It is up to the scientist's judgment which theoretical virtue is more important in a given case and how it is employed. This procedure cannot be precisely formulated.

It follows that by pointing at the virtues possessed by the theory we cannot describe or explain completely the choice of the scientists, nor can these virtues justify the outcome of their choice to the exclusion of other choices. Duhem recognized that even if we grant that all scientists agree globally on the importance of these virtues, they have the freedom to employ them differently and therefore might make different choices (Duhem, 1954, p. 288). Even though criteria to describe theory choice can be found, they cannot determine the choice uniquely. What can be concluded from this analysis is that the particular virtues of a theory do not suffice to justify an exclusive outcome in theory choice. In abandoning a particular

\footnotetext{
${ }^{6}$ It is important to note that Duhem's idea on the significance of theoretical virtues and their non algorithmic employment was also developed by Thomas Kuhn (1977). As Duhem, Kuhn suggested that we cannot provide an algorithm to be employed in theory choice but we can recognize certain 'values' that scientists share and recognize independently of the fact they belong to different paradigms. According to Kuhn, this list of theoretical virtues "accuracy, consistency, scope, simplicity, and fruitfulness .... provide the shared basis for theory choice" (Kuhn, 1977, p. 322). Similarly to Duhem, Kuhn stressed that these 'values' do not determine the choice of a paradigm but influence it, and that these choices cannot be justified "though the experience of scientists provides no philosophical justification for the values they deploy ... those values are in part learned from that experience, and they evolve with it" (Ibid, p. 335)
} 
hypothesis or in choosing a certain theory, scientists need to make judgments; they need to choose by weighing the theoretical virtues and they do this, according to Duhem, by employing their good sense.

Duhem argued that when we are faced with a negative outcome from experiment neither experience nor logic dictates which of the hypothesis must be abandoned; there is no "absolute principle" (Duhem, 1954, p. 216) to guide scientists, and in order to come up with a decision "everyone should follow his own methods" (Ibid, p. 99). A scientist may choose to keep some hypotheses which may be abandoned by another scientist; still, since logic does not impose a solution, they do not have the right to "accuse one another of illogicality" (Ibid, p. 216). Faced with a negative outcome from the experiment, one may either choose to preserve the existing theories by changing auxiliary assumptions to accommodate the new facts, or may replace the old theory with a fundamentally different one that accounts for the new and the old facts. Both moves are logically consistent and equally sound and it is the good sense of the scientist that guides him to which hypothesis is to be preserved. Their choice is justified only retrospectively by empirical evidence: "the methods they follow are justifiable only by experiment" (Ibid, p. 217). The fact that scientists seem to choose the right theories, the theories leading to a more unified and novel predictive theories, despite the problem of underdetermination, led Duhem to infer that there must be some characteristic of scientists which is responsible for their choice. To explain this fact, he invoked the concept of good sense. It is important to note that the choices of the scientists faced with theory choice come later on to be supported by empirical evidence and therefore this shows that they have made the right choices.

The fact that there is no strict rule to guide scientists when faced with the problem of underdetermination, but nevertheless they manage to make a choice which is later supported by empirical evidence, can be brought out by the following historical incident. When the 
observations of Uranus's orbit did not match the Newtonian predictions, scientists had two choices. They could either modify the theory or make the needed adjustments to the auxiliary assumptions. In order to explain why the orbit of Uranus was not the predicted one, scientists did not abandon Newtonian physics. On the contrary, they changed the auxiliary assumptions by supposing that there was a hitherto unobserved planet, Neptune, whose motion perturbs that of Uranus and is therefore responsible for its irregular motion. Few years later relevant observations confirmed Urbain Le Verrier's prediction of the existence of Neptune. In this case we see that changes in the auxiliaries were successfully made to save Newtonian physics. In the case of the irregular motion of Mercury, however, changes in the auxiliaries could not explain the phenomena and more radical moves were needed. Even though Le Verrier proposed the existence of the hypothetical planet Vulcan to be responsible for the perturbed motion of Mercury, changes in the auxiliaries could not save the theory. It was after the theory of relativity triumphed over Newtonian physics that the gravitational field equations explained the anomalous advance of the perihelion of Mercury. These historical episodes show that there is no recipe which will lead scientists to a unique decision. In some cases changes in the auxiliaries can save the theory, leading to a natural classification, whereas in other cases the only way to explain the phenomena is by the abandonment of the theory and the advancement of a new one. The point that needs to be stressed is that no algorithm can be provided to determine theory choice uniquely. Sometimes scientists may need to change auxiliary assumptions in favor of the theory, while other times no such "timid" move can lead to a solution and more "bold" moves are needed. The only guidance as to which path one is to follow is, according to Duhem, the scientist's good sense. The fact these choices are later supported by empirical evidence shows that good sense leads to the right choices, or as Duhem would put it, the choices which lead to a more unified theory growing to a natural classification. 
Let us examine more carefully what exactly good sense is. According to Duhem, good sense is "these motivations which do not proceed from logic and yet direct our choices" (Duhem, 1954, p. 217). It is a cluster of virtues scientists possess which in the cases of underdetermination allows them to weigh evidence impartially, "leaving their interests and passions aside" (Duhem, 1991, p. 43). These virtues, as Duhem noted, are intellectual as well as moral and they are employed by scientists in the case of theory choice in order to favor the hypothesis that will be more fruitful and lead to a theory that would resemble a "perfect theory". Good sense exists in every scientist to some degree and is found in agreement with common sense. Duhem believed good sense can be developed by every scientist and it can be cultivated and sharpened by training and practice. Since it leads scientists to choose more fruitful theories, every scientist ought to cultivate his good sense to increase scientific progress and to reach the desired end of science, which is a natural classification. According to Duhem "physicists may hasten this judgment and increase the rapidity of scientific progress by trying consciously to make good sense within themselves more lucid and more vigilant" (Duhem, 1954, p. 218). Also, he stressed that scientists should never let their personal interest guide them in their decision because this action delays the progress of physics. Even though good sense is employed to provide guidance where there is no strict recipe, this absence of strict algorithmic rules does not lead to relativity of scientific knowledge because by employing their good sense, scientists manage to promote theories which are later empirically confirmed. Duhem recognized that the concept of good sense cannot be justified or explained further, but it is necessary in order to explain the course of the history of science. Duhem was a great admirer of Pascal and he often said, paraphrasing Pascal, that good sense is 'these reasons which reason does not know' or 'reasons of the heart' (Ibid., p. 217), and used this to support his claim that no rule can be provided to describe exactly how scientists manage to choose among two rival theories. 
At this point Duhem faced a difficulty. Without explaining further what good sense is and how exactly it leads to choices, he maintained that it guides scientists to make choices which become part of a unified natural classification. No justification or further support as to what exactly these considerations that need to be employed are is given. He insisted that the history of science strongly supports the view that science progresses and that every new theory that comes into existence is founded on the already existing ones. In his own words, "Why give up the ideal of unified and perfectly logical theory when systems actually constructed have drawn closer and closer to this ideal?" (Ibid., p. 296). Nevertheless, it seems that the concept of good sense is posited post hoc to explain the history of science; it cannot determinate choice in the face of underdetermination. If two scientists faced with the problem of theory choice support two different theories, how are we to decide which scientist has good sense and therefore which theory to choose? Duhem recognized that good sense does not always reveal itself in the same manner and degree, but it eventually "comes out so clearly in favor of one of the two sides that the other side gives up the struggle even though pure logic would not forbid its continuation"7 (Ibid., p. 218). It is not clear, however, what can resolve this conflict of good sense, besides empirical evidence. Duhem admitted that both scientists can hold that they have good sense on their side until empirical evidence is available to support one of the two theories. As he noted, "if two different theories represent the same facts with the same approximation, physical method considers them as having absolutely the same validity; it does not have the right to dictate our choice between equivalent theories and is bound to leave us free. No doubt the physicist will choose between these logically equivalent theories, but the motives which will dictate our choice will be considerations of elegance, simplicity, convenience, and grounds of suitability which are

\footnotetext{
${ }^{7}$ According to Duhem (Duhem, 1954, p. 218), such is the case of Biot, who abandoned the emission hypothesis as the experiment of Foucault showed that light travels faster in air than in water. That was not an example of a crucial experiment which supported wave optics to the emission hypothesis. According to Duhem, it would have been simply a lack of good sense if Biot continued to resist wave optics.
} 
essentially subjective, contingent, and variable with time, with schools, and with persons; as serious as these motives may be in certain cases, they will never be of the nature that necessitates adhering to one of the two theories and rejecting the other, for only the discovery of a fact that would be represented by one of the theories, and not by the other, would result in a forced opinion" (Ibid, p. 288). It seems that on the one hand Duhem invoked the concept of good sense as a solution to the problem of underdeterminaion, while on the other hand he argued that it is not capable of leading to a determinate choice without (eventually) empirical evidence justifying it. If so, good sense seems insufficient to provide us a basis for choice; at best it seems to explain why a scientist chose a theory when we examine his choice. Therefore, it can be descriptive, but it cannot provide us with a solution when faced with the problem of theory choice.

Before moving to the next section in which we are going to examine possible interpretations of the concept of good sense, I would like to stress Duhem's motivations for developing the concept. Independently of whether we aim at constructing an empirically adequate theory, or a true theory, or a theory that leads to the real structure of nature, it is necessary to provide an account of rational choice. Good sense is an attempt to provide us with an explanation of how scientists choose theories that tend to become natural classifications of the observed phenomena. Also, even if we are in the first case, which is searching only for empirically adequate theories, it still seems quite simplistic to avoid trying to advance a normative theory of rational choice, since even the construction of an empirically adequate theory is not a simple procedure. Even an empirically adequate theory needs some intellectual virtues in order to be constructed. If we want to argue that rational choice is possible, we have to provide an account of how it is possible and what makes it possible. Duhem recognized that such an account will never be exhaustive; still, we can have 
some clue in virtue of what scientists may acquire theories that lead to the real structure of the world.

4. Duhem as virtue epistemologist

When discussing German science, Duhem pointed to the virtues that need to be employed by scientists in order to reach objective decisions: "in order to estimate correctly the agreement of a physical theory with the facts, it is not enough to be a good mathematician and skillful experimenter; one must also be an impartial and faithful judge" (Duhem, 1991, p. 218). Moreover, he stated that "In the realm of every science, but more particularly in the realm of history, the pursuit of the truth not only requires intellectual abilities, but also calls for moral qualities: rectitude, probity, detachment from all interest and all passions" (Ibid., p. 43). The fact that Duhem seems to take knowledge subject to the moral and intellectual qualities of the scientist, recently made David Stump (2007) link Duhem's concept of good sense with virtue epistemology. Stump notes that "Despite his holism and his famous thesis that it is always possible to save a scientific theory from refutation by empirical evidence, Duhem thinks that scientists are able to weigh evidence and to make decisions, and that the decisions they make depend on the intellectual and moral virtues of the scientist as a cognitive agent" (Stump, 2007, p. 151).

Stump believes that Duhem took knowledge to be dependent on the virtues of the cognitive agent as contemporary virtue epistemologists do. He believes we can link Duhem's views to those of Linda Zagzebski, who holds that a belief is justified just in case it is the sort of belief that an intellectually virtuous person would have. Virtue epistemologists, like Zagzebski, have tried to establish the close connection between epistemology and ethics. Contrary to traditional theories in ethics which focus on moral action, virtue epistemologists focus on the intrinsic features of a person in order to evaluate her action. By analogy, virtue epistemology focuses on the agent's intellectual virtues in order to evaluate her beliefs. As 
Stump puts it, "Zagzebski hopes that all epistemic evaluation can be understood as part of a theory of value that encompasses both ethical and epistemic evaluation" (Stump, 2007, p. 151). Zagzebski defines justified belief as the product of the intellectual virtues an agent possesses, as right actions are a product of moral virtues. Even though there is a dispute about what these virtues are, virtue epistemologists generally treat moral virtues as characteristic traits or dispositions, "an innate ability or acquired habit that allows one to reliably achieve some intellectual good, such as truth" (Greco, 2004, p. 3).

Stump maintains that both Duhem and Zagzebski make use of the same epistemic values, such as impartiality, intellectual sobriety, and intellectual courage. According to him, "Like contemporary virtue epistemologists, Duhem also takes knowledge to be dependent on the virtues of the knower. Scientists must have intellectual and, indeed, moral virtues in order to reach scientific knowledge, especially when choosing between empirically adequate theories" (Stump, 2007, p. 150). According to Stump, Duhem's theory indeed seems very similar to that of Zagzebski because first, they share "an ethical vocabulary of epistemic norms" (Ibid., p. 152), and second, they both try to show that morality, in Zagzebski's case, and theory choice, in Duhem's case, are not strictly rule governed. This means that no algorithm could be provided to determine what decision should be reached in a situation of moral choice or in choosing between empirically equivalent rival theories. According to Stump, "In Duhem's account of scientific theory choice, there is openness, since strict rules do not apply, but also objectivity. The source of this objectivity is the epistemic agent - the scientist who acts as an impartial judge and makes a final decision" (Ibid., p. 155). Connecting Duhem to virtue epistemology, according to Stump, gives us the opportunity to clarify the normative aspects of epistemology and also develop a non-rule governed account of theory choice. To that end - developing a non-rule governed theory of rational choice - 
Duhem did not focus on explicating a particular method, rather, he "emphasizes the choice of the scientist as a judge of a theory - as a moral agent” (Ibid., p. 153).

Let us examine Stump's interpretation more carefully ${ }^{8}$. A possible objection against Stump's reconstruction of the concept of good sense concerns the fact that Duhem and virtue epistemologists differ as to their epistemic aim. Virtue epistemologists try to define how we acquire justified true beliefs and theories, which, according to Duhem, is an unachievable end of science. At most, science can reach the true relations that hold among unobservables but can never offer us their intrinsic properties. As already noted, a true theory is a perfect theory which will classify in a natural order all observable and unobservable phenomena. According to Duhem, a perfect theory, which is a theory that will reflect the true ontological order, is not achievable: "we do not possess this perfect theory, and mankind will never possess it; what we possess and what mankind will always possess is an imperfect and provisional theory, which by its innumerable groupings, hesitations and repentances proceeds slowly toward that ideal form which would be a natural classification” (Duhem, 1954, p. 302). Since we do not have access to the unobservable, the best we can reach at the ideal end of science is a natural classification of the observed phenomena, which will reveal the structure unobservable entities have, without revealing their intrinsic properties. This means that there is an essential difference between Duhem and virtue epistemologists, since Duhem believes, contrary to virtue epistemologists, that we are epistemically restricted and that can never reach the true order of nature. Still, it can be argued against this objection that one can adopt a weaker thesis and support that even though natural classification may not reveal the truth about the unobservable, it will be true for the observable phenomena. Also, one may argue

\footnotetext{
${ }^{8}$ Virtue epistemologists are generally criticized for being unable to explain what exactly differentiates them from reliabilism, since it is not clear what distinguishes these intellectual and moral virtues from the epistemic virtues that are involved in reliabilism. As Fumerton puts it (Fumerton, 1994, p. 18), "why not simply travel the more straightforward reliabilist route and identify intellectually virtuous beliefs as those that result from a reliable process?".
} 
that it is legitimate to aim at a particular epistemic goal independently of whether this goal is achievable or not.

Another difficulty for the identification of Duhem as a virtue epistemologist concerns the essential difference in the motivation of virtue epistemologists and Duhem. Virtue epistemologists try to justify what it is to have a true belief, using the moral virtues of an agent. That is, they are in the business of justification. On the contrary, Duhem did not invoke the concept of good sense to justify the scientist's belief in a theory. As noted in the previous section, he recognized that we are justified to believe a theory is a natural classification only when empirical evidence comes to support it. He also noted that the highest test for our belief of a theory to be a natural classification is "to ask it to indicate in advance things which the future alone will reveal" (Ibid., p. 28). Therefore, a scientist is justified to believe that a theory is a natural classification only when some empirical evidence supports it or when the theory has become a "prophet for us" (Ibid., p. 27), that is, when it has managed to make novel predictions. The point is that good sense does not justify the choice of the theory, as Stump's reconstruction of good sense would suggest. Duhem did not develop the concept of good sense to answer when we are justified in believing that a theory is true or when it is more probable to be true; as already noted, he is not in the business of justification.

Duhem proposed the concept of good sense neither as a method of science nor to justify the scientist's belief in a theory. Good sense was invoked as a solution to a particular problem: theory choice. It cannot be seen as a method for constructing true beliefs nor as justifying them. Duhem developed a deductive account of scientific method, which is captured in the following four steps: "(1) the definition and measurement of physical magnitudes; (2) the selection of hypotheses; (3) the mathematical development of the theory; (4) the comparison of the theory with experiment" (Duhem, 1954, p. 21). Good sense does 
not determine the construction of a theory and it is not what justifies a belief in the truth of a theory. It determines the scientist's choice, but not uniquely. It restricts the scientist's choice by excluding some of the possibilities with which he is faced in theory choice. It does not lead to justified true belief, but simply to a temporal acceptance of a theory. The theories it leads to are not to be taken as true descriptions of reality but as tools for approaching a natural classification. I believe that even though Duhem took intellectual virtues to constitute an important part of scientific practice, literally interpreting Duhem as a virtue epistemologist does not fully capture his motivations and views on scientific method.

To sum up, I believe Duhem and virtue epistemologists differ as to their epistemic aim. Contrary to virtue epistemologists, Duhem believed that we cannot reach a true theory, but a natural classification of the observed phenomena. Also, there is an important difference between the motivation of Duhem and virtue epistemologists. Duhem did not invoke the concept of good sense in order to justify the scientist's belief in a theory, but in order to explain what restricts the scientists' choices and therefore provide a solution to the problem of theory choice. In spite of these objections, I think we can draw important conclusions from Stump's interpretation for a better understanding of good sense. Building on the idea that the intellectual and moral virtues can be seen as dispositions for behavior, a view I think most virtue epistemologists support, I will argue in the next section that Duhem's view on rationality in theory choice is more complex and requires seeing good sense as a virtue of an ideal scientist.

\section{Good Sense and Perfect Scientists}

Having examined the virtue epistemology approach to Duhem's concept of good sense, proposed by Stump, I would like to suggest another way to develop it. Firstly, we should recall the perfect theory invoked by Duhem. According to Duhem, a perfect theory "would be a complete and adequate metaphysical explanation of material things" (Duhem, 1893, p. 
68). Such a theory would classify the laws acquired by experiment in a natural way, in "an order which would be the very expression of the metaphysical relations that the essences that cause the laws have among themselves" (Ibid). This perfect theory is a true theory that cannot be reached; all we can reach at the ideal end of science is a natural classification. Still, the idea of this perfect theory is a helpful idealization that enables scientists to promote theories possessing the virtues of the ideal theory. A perfect theory possesses properties idealized from particular theories actually constructed in the history of physical theories. According to Duhem, "if we perceive in an instant's glance an isolated position of the ball that a tennis player has hit, we cannot guess the end point he aimed at; but if our glance has followed the ball from the moment his hand moved to strike it, our imagination, prolonging the trajectory, marks in advance the point that will be struck. So the history of physics let us suspect a few traits of the ideal theory to which the scientific progress tends, that is, a natural classification which will be a sort of reflection of cosmology.” (Duhem, 1954, p. 303).

In an analogous way, we can speak of an ideal scientist possessing various characteristics or virtues such as impartiality, intellectual sobriety, rectitude, probity and intellectual courage. We can idealize the properties and virtues of actual scientists into the properties and virtues of an ideal one. By omitting some of the properties of the actual scientists and by adding others that are not fully present in them, we can produce the perfect scientist, who, compared to the actual scientists, possesses some extra properties and lacks others. The actual scientists approximate and resemble to a different degree the action of the perfect one. It is important to stress that the ideal scientist is a product of idealization and abstraction and not of inductive reasoning, since the latter would come into conflict with Duhem's general methodology, given he did not favor induction.

Such an ideal scientist, of course, does not exist; however, we can speak of an ideal agent capable of performing ideal operations along the lines of Kitcher, who maintains that 
"Just as we abstract from some of the accidental and complicating properties of actual gases to frame the notion of ideal gas, so too we specify the capacities of the ideal agent by abstracting from the incidental limitations on our own collective practice" (Kitcher, 1985, p. 117). Even though these virtues are present in every scientist to some degree, Duhem noted that in every science there are some scientists that serve as a model that should be followed, scientists who were "able to make the proper distinction between the intuitive and the mathematical minds, where penetrating intuition has sensed the principles and a rigorous deduction concluded to the consequences" (Duhem, 1991, p. 71). These scientists who serve as a model to all, possess various properties (virtues) and if we follow the line of Duhem's thought on the ideal theory, we can conclude that history provides us with 'traces' of perfect scientists, like Newton, Huyghens, Lagrange, Laplace, Pascal, Guy-Lussac, Amperé, Sadi Carnot, (ibid), the virtues of whom can be idealized into the properties of an ideal scientist who should serve as an example to all practicing scientists.

Considering good sense as a collection of virtues that an ideal scientist possesses has several advantages. First, it helps us explain why scientists aim at being impartial and why their practice sharpens their good sense. Having the idea of a perfect scientist helps actual scientists develop their skills and try to resemble and act as an ideal scientist would act and it shows them which characteristics and virtues they ought to develop in order to promote scientific progress. We can explain why scientists develop their good sense with practice, since good sense is a cluster of dispositions that are developed through experience. Second, considering good sense as a product of idealization from the virtues of actual scientists into the virtues possessed by a perfect one seems to offer another advantage: it is descriptive of actual scientific practice. Since actual practicing scientists serve as the raw material for the construction of the perfect scientist, it is descriptive exactly because we construct the perfect scientist by idealizing the actual properties of practicing scientists. We can reach actual 
scientists by the process of de-idealization from the perfect scientist. This preserves Duhem's aim of providing an account of rationality in theory choice that describes actual scientific activity.

Another important advantage of viewing good sense as a property of a perfect scientist is the fact that it seems to help us overcome the charge that Duhem's rationality is retrospective. As pointed in section 3, Duhem undermines his thesis that good sense can guide scientists to a conclusive choice by saying that only empirical evidence conclusively solves and justifies the problem of theory choice, making the concept of good sense post hoc. But there seems to be a way out of this retrospective character of good sense. By asking themselves what a perfect scientist would do in a particular situation, scientists can employ counterfactual reasoning which can shape the outcome of their decisions and actions. This cluster of virtues which we idealize into the properties of an ideal scientist help us make the concept of good sense prospective, since it can answer prospective questions and therefore can assist practicing scientists when faced with the problem of theory choice. As examined earlier, scientists possess various criteria (the virtues of the theory), which are to be employed in theory choice. These criteria can help us to describe, explain and justify the scientist's decision, but they do not do that uniquely. The problem of theory choice cannot be solved by pointing at some criteria because scientists need to make judgments and weigh these theoretical virtues, and the concept of good sense was employed exactly because Duhem wanted to explain how this is done. If we consider good sense as the properties of a perfect scientist, we can achieve this because the choice of the scientists can be guided by what the perfect scientist, who possesses virtues as impartiality, rectitude, probity, who takes into consideration all evidence, would do. Good sense, then, seen as the properties of a perfect scientist, is neither used as a guide to true theories, nor as justifying the scientist's 
belief in a theory, but is choice conclusive. It can serve as a guide to scientists when no empirical evidence can determine which of two (or more) rival theories should be chosen.

Let us describe the characteristics of Duhem's account of rationality in theory choice. First, Duhem departed from normative theories of rationality ${ }^{9}$ because he wanted to account for actual scientific practice and therefore did not want to restrict theory choice to some algorithmic procedure. On the other hand, he tried to avoid relativism and to offer a general account which can help scientists promote theories growing to a natural classification. The interpretation of the concept of good sense I examined in this section does not suggest that Duhem was involved in any kind of epistemic justification, which in my opinion would not capture his motivations for developing the concept of good sense. It provides us with a theory of rationality that is loose enough, since it does not restrict scientists to some particular algorithmic rules. On the other hand, the concept of good sense provides general guidance since scientists will need to apply particular skills and virtues in order to promote theories possessing particular virtues. While offering loose guidance, Duhem's account of rationality in theory choice avoids relativity on the one hand and strict formal rules on the other hand. What the concept of good sense does is serve as a permissive account of rationality, since it excludes possibilities but does not dictate what should be chosen. It is well known that Duhem draws a middle way between scientific realism and instrumentalism. As I see it, he makes the same move in his theory of rationality in theory choice: instead of offering simply descriptive or normative theory, he tries to provide a theory strong enough so that it provides guidance to scientists when they are faced with the problem of theory choice, but also loose enough so that it should not be very restrictive to scientists.

6. Conclusion

\footnotetext{
${ }^{9}$ The distinction between normative and descriptive theories of rationality is a product of modern debate and is discussed in Lipton (2005).
} 
By stressing the importance of intellectual virtues in theory choice, Duhem's complex view of rationality helps us recognize that judgment is part of scientific practice. Duhem realized that scientific practice cannot be described as the following of algorithmic rules. We have to consider the involvement of virtues and values in theory choice, but this need not account to a denial of rationality. By invoking the concept of good sense, Duhem accounted for the rationality in science and avoided relativism since he provided some general guidance to scientists faced with the problem of theory choice. I have argued that the concept of good sense can be best understood if, by extending Duhem's ideas about the properties of the perfect theory, we construct by analogy the concept of a perfect scientist. This idealization of a perfect scientist can help us overcome the retrospective character of good sense and therefore preserve Duhem's ambition of both accounting for how scientists actually choose among empirically equivalent theories but also explaining the normative dimension of theory choice.

Acknowledgements

I wish to express my deep gratitude to Stathis Psillos, James Ladyman, Theodore Arabatzis, John Worrall, Stelios Virvidakis and three anonymous referees for valuable comments on this paper.

Research for this paper was funded by the framework EPEAEK II in the programme Pythagoras II while the author was at the Department of Philosophy and History of Science in the University of Athens.

\section{References}


Duhem (1996) Some Reflections on the Subject of Physical Theories Physics and Metaphysics. In R. Ariew, \& P. Barker (Eds.), Pierre Duhem: Essays in the History and Philosophy of Science (pp. 29-50). Indianapolis: Hackett. (First published 1892)

Duhem, P. (1996). Physics and Metaphysics. In R. Ariew, \& P. Barker (Eds.), Pierre Duhem: Essays in the History and Philosophy of Science (pp. 29-50). Indianapolis: Hackett. (First published 1893)

Duhem, P. (1954). The Aim and Structure of Physical Theory. Princeton: Princeton University Press. (First published 1906)

Duhem, P. (1969). To Save the Phenomena. (E. Doland, \& C. Mascher Trans.). The University of Chicago Press. (First published 1908)

Duhem, P. (1991). German science: Some reflections on German science: German science and German virtues (John Lyon, Trans.). La Salle, IL: Open Court. (First published 1915)

Fumerton, R. (1994). Sosa's Epistemology. Philosophical Issues, Vol. 5, 15-27.

Greco, J. (2004). Virtue epistemology. In E.N. Zalta (Ed.), The Stanford encyclopedia of philosophy, http://plato.stanford.edu/entries/epistemology-virtue.

Hoefer, C. and Rosenberg, A. (1994). Empirical Equivalence, Underdetermination, and Systems of The World. Philosophy of Science, 61, pp. 592-607.

Kitcher, P. (1985). The Nature of Mathematical Knowledge. Oxford University Press.

Kuhn, T. (1977). Objectivity, Value Judgment, and Theory Choice. In The Essential Tension (pp. 320-353). The University of Chicago Press.

Ladyman, J. (2002). Understanding Philosophy of Science. Routledge.

Lipton, P. (2005). The Medawar Lecture 2004: The truth about science. Phil. Trans. R. Soc. $B, 360,1259-1269$.

Lugg, A. (1990). Pierre Duhem's Conception of Natural Classification. Synthese, 83, 409420. 
McMullin, E. (1990). Comment: Duhem’s Middle Way. Synthese, 83, 421-430.

Psillos, S. (1999). Scientific Realism - How science tracks truth. London: Routledge.

Stump, D. (2007). Pierre Duhem's virtue epistemology. Studies in History and Philosophy of Science, 38, 149-159.

Worrall, J. (1996). Structural Realism: The best of both worlds?. In D. Papineau (Ed), The

Philosophy of Science (pp. 139-166). Oxford: Oxford University Press. (First published 1989)

Zagzebski, L. (2003). The Search for the source of Epistemic Good. In M. Brady, \& D. Pritchard (Eds.), Moral and Epistemic Virtues (pp. 13-27). Blackwell Publishing. 